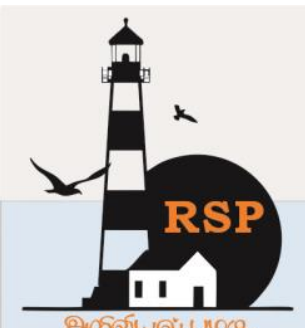

INTERNATIONAL RESEARCH JOURNAL ON ADVANCED SCIENCE HUB

RSP SCIENCE HUB

(The Hub of Research Ideas)

Available online at www.rspsciencehub.com

\title{
COVID-19 Impact on Education Sector: Measure and Strategies, Morocco as a case Study
}

Fatima Ezzahra Ech-Chorfy ${ }^{\text {, }}$

language and society, University Ibno Tofail, FLSH kénitra, Morocco.

fatimanour01@gmail.com

\section{Abstract}

Starting from March of 2020, the explosion of the COVID-19 causes the global education system to close and forced it to alternatively opt for immediate online teaching practices. All nations are surrounded by a context where millions of students are no more in the classroom and the only left option is the off class teaching. The Moroccan education system is one example among many others. On its turn it, switched right away to procedures and decision required by such urgent situation of confinement. This paper focuses on a case of Moroccan national education system. Different strategies are presented to summarise the current online teaching experience in Morocco. The study concludes with eight impact principles for online education: (a) high relevance between online teaching design and student learning, (b) prior planning of online teaching contents, (c) adequate assistance and psychological support to students, $(d)$ reduced fear, pressure, and confusion creates a suitable online learning environment (e) high participation improves student engagement and online learning outcomes, $(f)$ support and supply technologically-based education resources, $(g)$ equip and train instructors with tools and techniques to using online education platforms, $(h)$, design online emergency programs and plans to serve in unexpected situations.

Keywords: Covoid-19, Education Strategies and Measures, Impact Principles.

\section{Introduction}

The year 2020 is an exception in the history, the pandemic covid-19 that surprisingly spreads out all over without exception starting from china, has changed all life fundamentals. Education is classified among the number one sector to be highly influenced by it. Morocco has been experiencing an unprecedented enormous change. It moved its national education system, starting from primary to higher education, from in-class education to online education. Following the government's order of non- stopping education during the quarantine period, the education official and policy makers launched an urgent plan of online teaching. This online teaching relied mainly on the screens of computers, mobile phone and iPods. Accordingly to what happened all over the world, This step was taken to keep all students and of all levels and streams at home safe while takes online classes and courses. In a short time period, millions of faculty members and school teachers started to teach in front of a computer screen, while students are asked to stay at home and take courses. With the spread of COVID-19 across the world, about 61 countries in Africa, Asia, Europe, the Middle East, North America, and South America have announced their regulation of teaching online from home and it implemented this in schools and universities Therefore, all universities and schools are declared to experience a localized closure (UNESCO, 2020). The paper identifies the Moroccan education followed measures and the impact of principles and 
strategies of education that would help in future online teaching experiences in such nonanticipated conditions. [1-4]

\section{CASE CONTEXT -COVID-19}

Morocco has earlier developed a Strategic Vision 2015-2030, which has been approved as Law 51.17 in 2018. It aims at improving the quality of education, achieving social justice, and responding to today's job market needs of human resources and qualifications. The vision, in its globe, put more focus on equity development among learners in different levels, regions, and ages as a factor of developing the national education system and achieving the social equity in large. (Loi Cadre 51.17, 2019).

Information and communications technology (ICT) becomes part and parcel of everyday practices, and 21st century learners are very different from old generations because they are born with technologies surrounding them and therefore become native users of technology or as Prensky (2001a) called them 'digital natives' (Prensky, 2001a). The Moroccan Education Reform 51.17 has taken these changes into consideration. Article33 makes a statement about: (1) integrating ICTs to develop quality education and enhance students' performance, (2) creating laboratories to build digital education resources and form and train specialists in the field, (3) develop distant-learning since it has been considered complementary to inclass learning, and (4) integrating e-leaning gradually until it circulates to reach all schools in rural and urban areas. All of these measures are to develop quality education, make better performance, and respond to learners' needs and 21st century school requirements (Higher Council, 2015, pp. 17-18). However, the implementation of these strategies and measures aware said to take time and be applied on a long term processes. [5-7] The outbreak of COVID-19 was put in mind or expected it forced part of this reform which is concerned with ICTS and e-learning to emerge in a short period and before set time. According to minister of Education, Saïd Amzazi, the number of students reached 7,9 millions of in the year 20182019 where $52 \%$ are females, $14 \%$ have integrated in private sector, and 742.000 are newly enrolled . $49 \%$ of the total number are college students enrolled in 23 universities, 202 public institutions, and 212 private institutions. Nearly, 600,000 Moroccan students use daily the online learning TelmidTICE platform launched by the ministry of education and about nearly 3 million people participated in online courses of college.

\section{CASE FOCUS - Online Education}

Switching all in-class courses to online teaching in a very limited time is disruptive because such shift requires time, efforts, techniques, and strategies. For courses online to be effective and successful, there should be some fundamental aspects. First this process required good prior planning and content design. What is to be taught in classes would not be appropriate online regardless of having almost the same content or lessons. A specific teaching material is required including that audio, and video contents as well as the support of technology professional teams. All of these requirements are not effectively met because of sudden appearance of COVID-19. In this case both instructors and learners are facing challenges of lack of experience, equipments, early preparation, trainings, or support of technology and ICT professionals. Learners in this context are confused because of the tendency to attend in-class courses and lessons. Now, they regard themselves in a new emerging context of online teaching which is not there as complementary to primary education but as replacing one.

\section{CASE MEASURES}

The Moroccan national education opted for the following measures to keep students on the learning process from at-home. For primary, secondary and high school, the procedures are

1. TelmidTICE is a platform to support and develop distance education. The Minister of National Education, Vocational Training and Scientific Research addresses to primary and secondary school pupils and students. It provides e a set of digital resources in the form of videos and summaries in addition to online exercises. Some 600,000 Moroccan students use it on a daily basis

2. The national education portal to broadcast produced education contents and courses ( https://soutiensco.men.gove.ma) . Over 3000 courses covering a wide variety of subjects 


\section{www.rspsciencehub.com}

including science, mathematics, physics, languages and others are accessible to primary and secondary education students thanks to this web site which has enabled them to continue their learning.

3.The national TV channels: "Athaqafia", "Laayoune TV" and " Tamaghirt TV" .The rural areas are deprived of distance learning because of net coverage or poverty that would not enable accessing these platforms. Therefore, the ministry of education decided to broadcast education content on these TV channels aiming at equally reaching largest number of students.

4.Some teachers contacted their students and delivered their lessons and courses via some other platforms that allow file transfer, and video teamwork such as Microsoft teams and Classroom, Zoom, Facebook live, and Google meet.

Regarding students in college and higher education, each university has added a box in its platform in which the students can find the day and time of the course online. Professors relied much on Microsoft teams and Classroom and Zoom platforms to facilitate team work through video conferencing, talks and messaging where everyone can interact with the group.

\section{IMPACT PRINCIPLES}

Based on observations of online teaching at ERRAZI high school and meetings with professionals in field of education, this paper classifies eight instructional principles to improve students' online learning engagement, interest and focus and to quarantine a smooth successful transition from in-class courses and lessons to online learning.

1 First, create high relevance between online teaching design and student learning

Instructors often fail to make the connection between what we do in a physical classroom and what we do online. There should be an explicit connection between what you do well in person and what you do online. And these online content designs should be relevant.

2 Second, make prior planning of online teaching contents crucial
Since online contents differs highly from classroom contents in that the first required other tools and teaching material to maintain video conferencing and voice interaction, prior planning of online material should be considered. Prior would also prioritise selections of content and strategies to ensure students would focus in the online-classes. Many students have shown weak persistence, concentration and interest in online learning, which seriously restricted their learning outcomes. In order to ensure that students concentrate on online study, instructor should also consider dividing the content into small units or modules where timing won't exceed 20-25 minutes.

3 Third, provide students with adequate assistance and psychological support

Students in a new learning context need support and assistance more any time ever. They need to feel they aren't alone at home but there are assistants who are ready to help them on academics when needed. Students within COVID-19 need psychological support. In very school there should some assistants devoting time to online support of students and guidelines.

4 Fourth, reduce fear, pressure, and confusion creates a suitable online teaching environment

It's very usual that experiencing new learning environ drives with it pressure, fear and confusion. Unlike the in- class learning where students feel more confident and encouraged by their classmates, the online learning, in introduces sort of confusion with regard to content, way, learning, the new required tools and accessed platforms. This leads to feelings of fear and also pressure, teacher on their turn have to reduce these feelings and create good relaxing online learning environment. They can do that by preparing learning at the first 10 minutes of a lesson and putting in their mind an idea of online is not far reached or different from remote learning.

5 Fifth, ensure high participation to improve student engagement learning outcomes

Focusing on techniques and activities that push learner to participate online would improve their engagement. The progress of online teaching and learning fully depend on students' engagement in online-classes and active learning. For this, teachers should use various methods to moderately 
modify students' homework and assignments to strengthen their learning outside of class and encourage online classes high participation.

6 Sixth, support and supply technologically-based education resources and combine online with offline

Preparing education resources that can also be used offline. Learners can refer back to them in case of need. These resources and online teaching should be managed to combine with everyday in-classes practices.

7.Seventh, equip and train instructors with tools and techniques to using online education platforms

The technical requirements of online teaching are larger than traditional in-class teaching for inexperienced teacher, instructor or faculty members. Learner, on the other side, need to be equipped with tools and technique to cope up with online learning requirements. Yet, learners or students are not expected to do much about because teacher and professor who are supposed to monitor and operate online education platforms. Teachers and faculty members are not well trained. Hence, they need to be trained on using such platforms. In addition, there should be teaching assistant as well as technology professionals who would communicate with faculty member and teachers at schools to make sure they understood objectives and teaching activities suitable for each teaching experience. These assistants will also help students who are acquainted with these platforms to assist them on their use and also their question either through mails or other online chat Boxes.

8 Eight, design emergency online programs and plans to serve in of unexpected situations.

The COVID-19 pandemic has resulted in educational institutions being compelled to suddenly utilize technological tools to create content and conduct online courses. For educators, these are ne challenges and possibilities that need some potential. Ministry of education should design a range of online programs and set prior planning to keep ready for use in urgent cases or unexpected situation. It must also consider negative sides of technology. That is, it should know how sort out problems of net coverage, shut down of platforms, or computers serves limited host with plan B or at least inform students in advance.

\section{CONCLUSION}

The COVID-19 crisis reshape the politics of education and allow Technology to step into the breach. A shift to homeschooling and fully virtual instruction necessities a change in strategies and tactics of teaching and a certain adaptation to current situation particularities. The paper conclude eight impact strategies to better prepare our young learners for this emerged online teaching based on the case analysis of online teaching in one of Moroccan high schools. Because of characteristics of students, new learning environment, low concentration and engagement in online education, length of teaching content, students non-readiness to such sudden change, students' behavior, pressure and confusion, it is significant to adjust teaching speed, content, and time to ensure effective delivery. Teachers have to be guided and assisted on using technical tools for online teaching. Student on other side should be supported through emails and feedbacks. In addition, there should be some measures to encourage and guarantee high participation in the online learning process. Assignment and homework must be adjusted to ensure active out class learning and engagement. In short, Students confusion and stress has to be relived and policy makers together with technology professionals and teacher collaborate to make ready an emergent plan for similar occasions.

\section{References}

[1]. Amzazi. Said (2020). Parliament Speech of the Results of distance learning in Morocco, 21 June, 2020 from: https://www.men.gov.ma/Ar/Documents/M Amzazi-Prlmnt180520.pdf

[2].Higher Council. (2015). For a School of Equity, Quality and Promotion: A Strategic Vision of Reform 2015-2030. Higher Council for Education, Training and Scientific Research.

[3]. Higher Council. (2019b). Cadre de performance $\mathrm{du}$ suivi de la vision stratégique à l'horizon 2030: niveau national 2015-2018. Higher Council for Education, Training and Scientific Research

[4]. OECD (2015), Education policy outlook 2015 : making reforms happen., OECD Publishing,

Paris, 
http://dx.doi.org/10.1787/9789264225442-

en.

[5].Prensky, M. (2001b). Digital Natives, Digital Immigrants, Part 2. On the Horizon, 9 (6), 1-6 in Solomon, G. (2010). Education for the 21st Century: The Basics. Retrieved, 10 March, 2020 from http://www.smlcs.org/publications/21stcent uryeducation.pdf.

[6].Sobhi.T, Sophie C, Amapola A. 2010 éducation au Maroc: analyse du secteur. UNESCO. Cluster Office for North Africa, 2010.

[7].UNESCO. (2020, Match 13). COVID-19 educational disruption and response. Retrieved from https://en.unesco.org/themes/educationemergencies/coronavirus-school-closures Google Scholar 